EMBRYARIDDLE
Aeronautical University

SCHOLARLY COMMONS
International Journal of Aviation, Aeronautics, and Aerospace

\title{
Wingtip Vortex Alleviation Using a Reverse Delta Type Add-on Device
}

\author{
Afaq Altaf \\ New York Institute of Technology, afaqaltaf@hotmail.com
}

Follow this and additional works at: https://commons.erau.edu/ijaaa

Part of the Aerodynamics and Fluid Mechanics Commons

\section{Scholarly Commons Citation}

Altaf, A. (2017). Wingtip Vortex Alleviation Using a Reverse Delta Type Add-on Device. International Journal of Aviation, Aeronautics, and Aerospace, 4(3). https://doi.org/10.15394/ijaaa.2017.1178

This Article is brought to you for free and open access by the Journals at Scholarly Commons. It has been accepted for inclusion in International Journal of Aviation, Aeronautics, and Aerospace by an authorized administrator of Scholarly Commons. For more information, please contact commons@erau.edu. 


\section{Wingtip Vortex Alleviation Using a Reverse Delta Type Add-on Device}

\section{Cover Page Footnote}

The author is indebted to International Islamic University Malaysia and Monash University Malaysia for supporting this work. 
Due to continuous air traffic growth, existing separation rules are becoming extremely insufficient at coping with future air traffic requirements. This study is driven by the objective of reducing the present air traffic spacing, while sustaining the same level of safety.

All aircraft create wake vortices, an unavoidable result of the creation of lift. Vortices from wingtips have been observed to persist for many miles. This poses a serious threat to following aircraft, particularly when the following aircraft are small and must fly in close proximity to the airport runway during take-off and landing. This is a time when wake vortex circulation is at a peak level (Andrews, 1970; Arndt et. Al., 1991; McGowan, 1968). An aircraft's position and alignment with respect to the wake shed by a large lead aircraft is of major concern, as the following aircraft may experience sudden up-wash or downwash, intense roll motions, and/or abrupt altitude loss (Ortega et al., 2002).

Turbulence created by an aircraft's wake has caused numerous, devastating accidents at low altitudes during landing approaches because pilots often do not have sufficient time to regain complete control of their aircraft after encountering significant turbulence. Statistical data about wake turbulencerelated accidents indicates that more than half of the accidents occur during approach and landing; most accidents occur at very low heights; and $90 \%$ of accidents involve small aircraft. In $99 \%$ of reported events, the effects of wake turbulence were abrupt, and occurred without any warning (Veillette, 2002).

The International Civil Aviation Organization (ICAO) has prescribed a minimum separation criterion between two aircraft during takeoff, approach, and landing to help aircraft avoid the affects of wake turbulence (Elsenaar, 2006). The regulations include segregating aircraft by size, controlling flight paths during take-off and landing, and keeping a fixed separation between aircraft based on the scale of the lead aircraft. The current spacing rules in place are based on worse case scenarios, and allow far more separation distance between aircraft than is needed to avoid accidents (Babie \& Nelson, 2004). However, the financial repercussions of these separation requirements are staggering (Matalanis \& Eaton, 2007). Since it is impossible to eliminate aircraft wake vortices, ways of reducing their intensity in the shortest time/distance should be considered.

Researchers have studied multiple vortex pair systems generated by aircraft with multiple flaps. These have shown to create weaker wakes (Fabre et.al., 2002; Durston et. Al., 2005; Savas, 2005). Many devices have been used to upset the vortex roll-up and form a weaker resultant vortex. (Corsiglia et al., 1971; Patterson, 1975; Breitsamter, 2011; Lee and Pereira, 2013; Altaf et al., 2016). Several studies have been carried out with reverse delta type add-on devices and suggest that they can be used in vortex alleviation (Breitsamter, 2011; Altaf et al., 2016). Reverse delta type add-on device vortices appear to 
instill counter-sign vorticity into the wingtip and flap-tip vortices, upsetting the vortex roll-up (Altaf et al., 2016). The interaction of the vortices creates an enlarged and weaker resultant vortex, which enhances wake vortex decay.

This study attempts to show that using a reverse delta type add-on device can help minimize the wake vortex hazard posed to the following aircraft. This investigation is a continuation of the wake vortex alleviation studies previously carried out by the author using a reverse delta type add-on device (Altaf et al., 2016).

\section{Method}

The $6.0 \mathrm{~m} \times 2.3 \mathrm{~m} \times 1.5 \mathrm{~m}$ wind tunnel at International Islamic University Malaysia was used to carry out the experimental work. The freestream turbulence intensity of the wind tunnel is less than $0.11 \%$. The Particle Image Velocimetry (PIV) charge coupled device (CCD) camera was placed in the flow stream at an approximate distance of three wing mean chord lengths downstream of the measurement plane, resulting in nominal disturbance to the upstream flow. Zhang et al. (2006) found the influence of a blunt object, placed in the wind tunnel, on the flow in the measurement plane to be less than five percent on the scattering of vortex centers, and less than two percent on the maximum vorticity, if the distance between the measurement plane and the blunt object exceeds two mean chords of the experimental model. For this study, the effect of the CCD camera on the flow is considered to be negligible, since it is more than two mean chords away from the measurement plane.

\section{Model}

This research work uses a half-span wing model at High Lift Configuration (HLC), shown in Figure 1, with two sets of reverse delta type add-on devices, shown in Figure 2. The add-on device is secured to the halfspan wing by a 35 millimeter high mounting. The geometric size of the reverse delta type add-on devices (for simplicity; the subscript rdw [reverse delta wing] will be used) was selected based on the lift and drag penalties associated with them.

\section{Procedure}

The velocity measurements at four downstream locations are studied; $x /(b / 2)=0.021,0.548,1.075$, and 2.387. The stream-wise distance, $x$, is measured from the wingtip to the laser sheet position. The experimental setup is shown in Figure 3. The free stream velocity in the wind tunnel was fixed to $12 \mathrm{~m} / \mathrm{s}$, which corresponds to a mean chord-based Reynolds Number, $R e_{c}=$ $2.75 \times 10^{5}$. One micrometer-sized seeding particles were used to study the flow dynamics. 

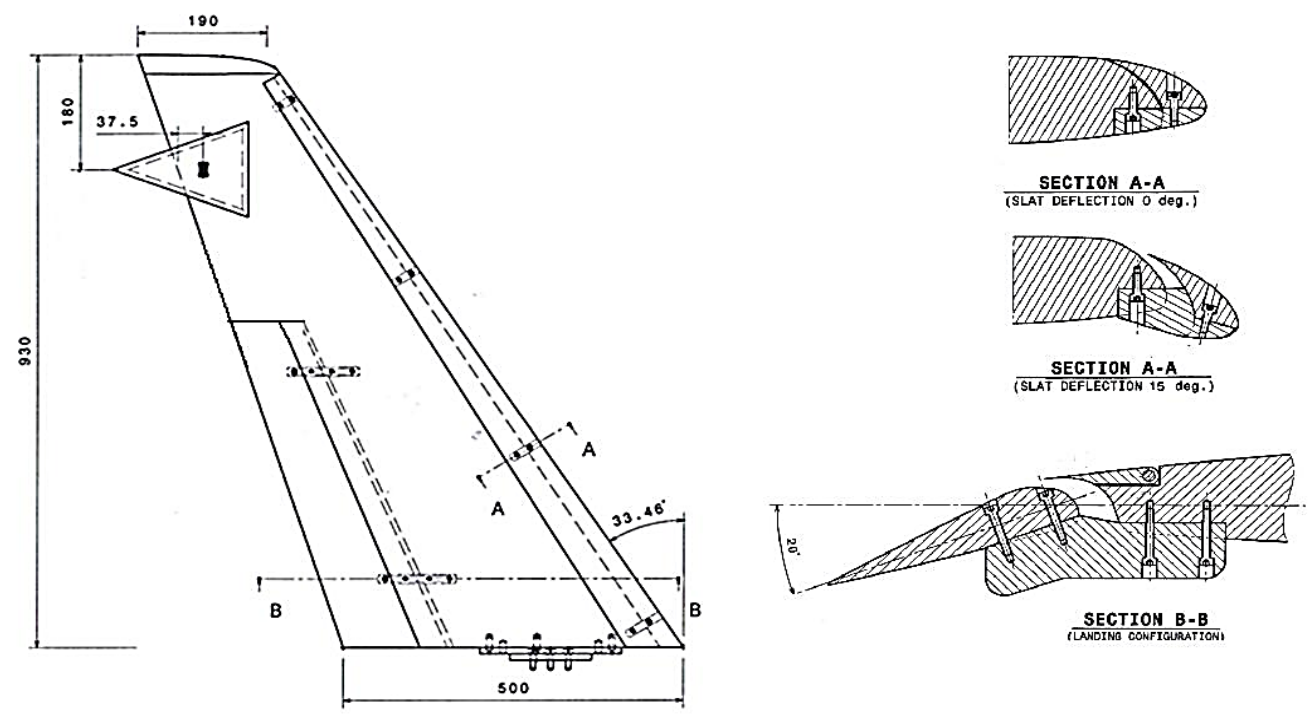

Figure 1. Schematic of the L-rdw attached to the half-span wing model.
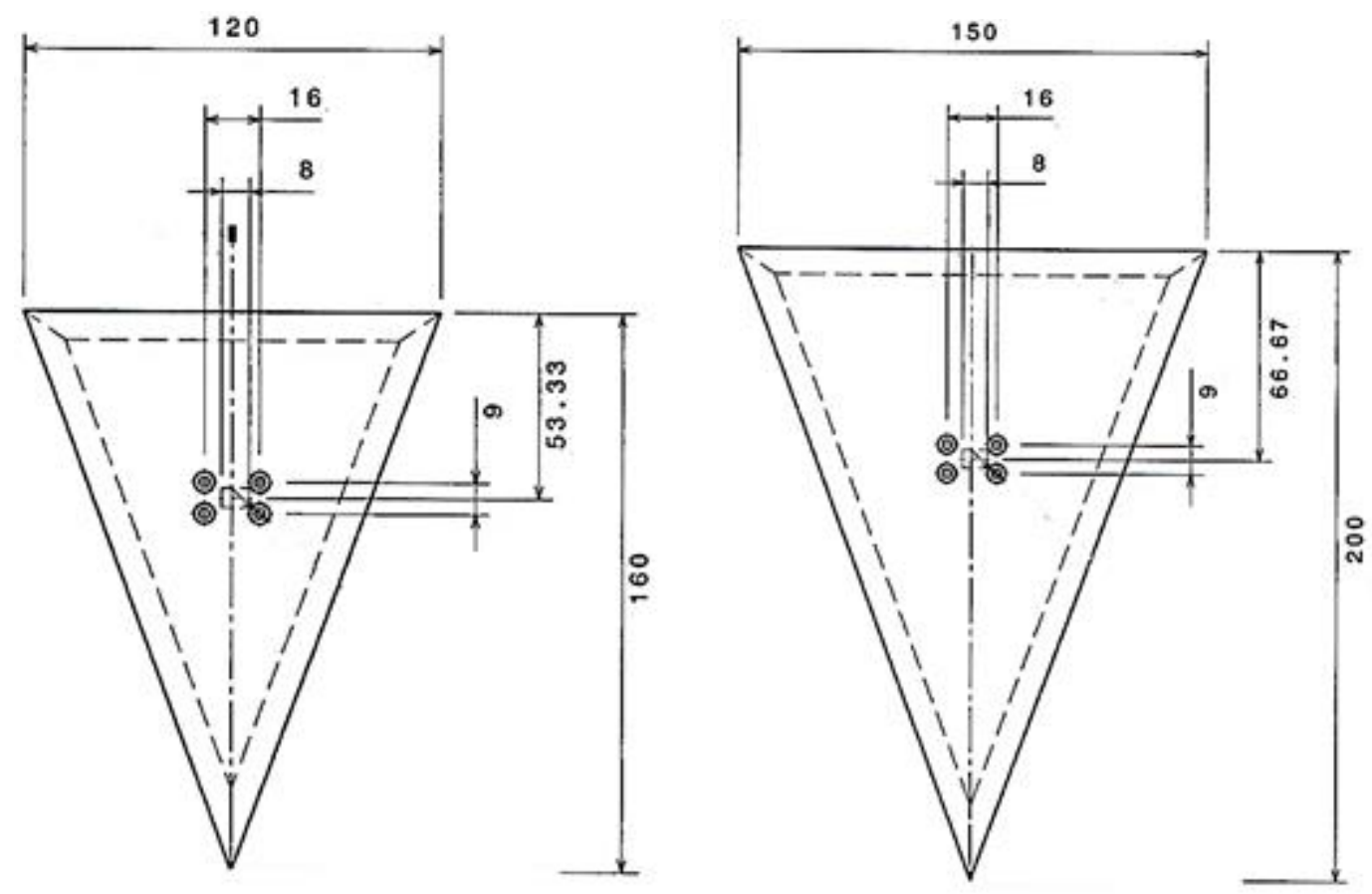

Figure 2. Schematic of the S-rdw (left) and L-rdw (right). 
WND TUNXEL TEST SECTION

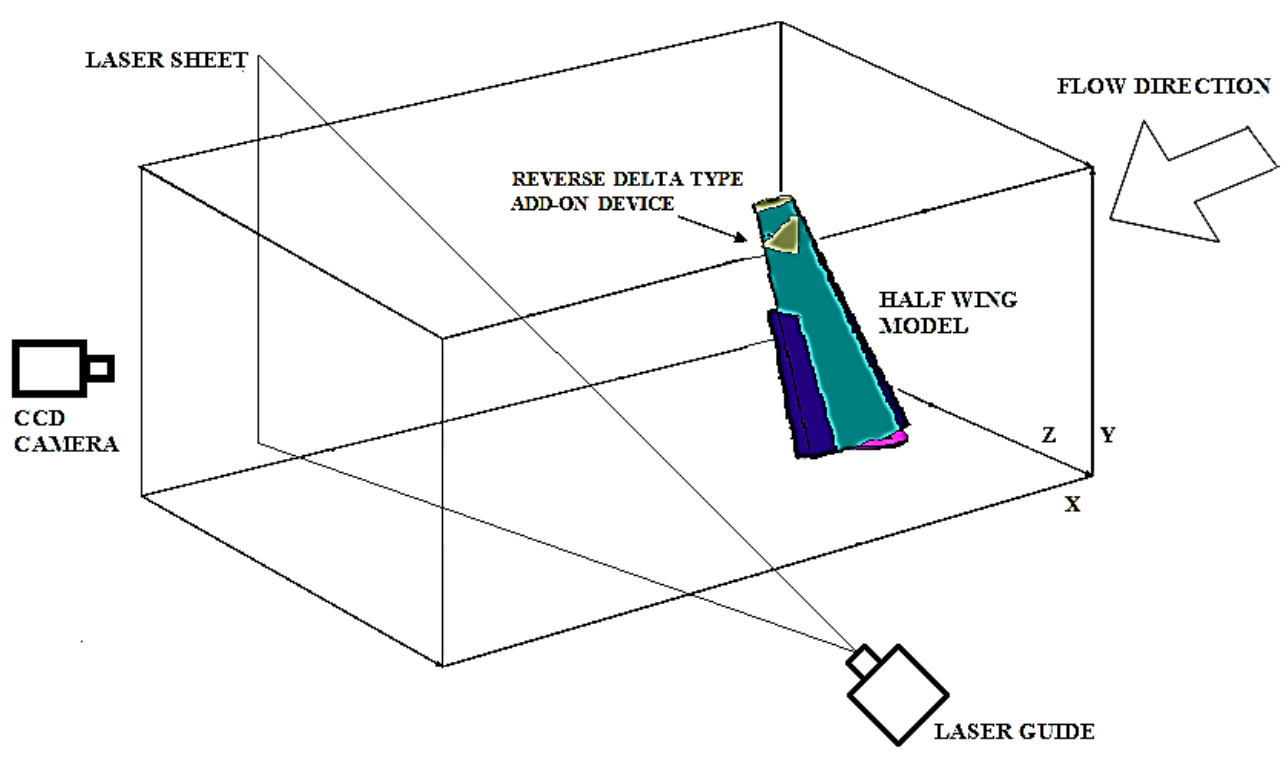

Figure 3. Schematic of the experimental setup in the wind tunnel.

It was found that at $\alpha=7.7^{\circ}$, the HLC case (slat configuration $15^{\circ}$, flap configuration $20^{\circ}$ ) yields a target lift coefficient $C_{L}=1.06$ and for the HLC with the reverse delta type add-on device, a $2^{\circ}$ increase in the half-span wing angle of attack is required to recover the target lift coefficient. Therefore, PIV data was obtained at $\alpha=7.7^{\circ}$ for the HLC case, and at $\alpha=9.7^{\circ}$ for the HLC with the reverse delta type add-on devices.

\section{Results}

\section{Velocity Vectors and Vorticity}

The purpose of the half-span wing model - reverse delta type add-on device configuration - is to determine if the vortices shed by the reverse delta type add-on device will inject instability (counter-sign vorticity) into the wingtip vortex and upset the roll-up process of the resultant vortex. The velocity vectors, tangential velocity magnitude, and vorticity magnitude of the HLC, with and without a reverse delta type add-on device, are shown in Figures 4 to 7.

Figures in the appendix show that the wingtip vortex is nicely rolled up, and more compact at a farther downstream location, indicating a strong vortex. 
The reduction in tangential velocity magnitude between downstream planes is minimal.

Figures in the appendix show that the tangential velocity magnitude reduction is much greater when a reverse delta type add-on device is used. Also, the resultant vortex core size is seen to be increasing significantly between the downstream planes.

In the HLC case, the wingtip vortex tangential velocity magnitude is steady between downstream plane 1 and downstream plane 3 . The wingtip vortex records a slight reduction in tangential velocity magnitude at downstream location 4 . This suggests that the wingtip vortex is strong. At downstream plane 4 , the add-on device cases exhibit higher tangential velocity magnitudes than the HLC case. This happens because the add-on device blocks the flow in its vicinity, forcing the flow to move around the reverse delta type add-on device. The flow then moves along the span of the wing towards the wingtip and flaptip. This accelerates the flow towards the wingtip and flap-tip, causing the existing flow at the wingtip and flap-tip to also accelerate.

At farther downstream planes, the fluid physics are different as corotating and counter-rotating vortices (counter-sign vorticity exists) shed by the half-span model wingtip and the add-on device exist and merge to form a weaker, diffused resultant vortex. The tangential velocity reduction from downstream plane 1 to 4 for the HLC is only $7.6 \%$, the tangential velocity reduction between HLC and HLC with the add-on device at downstream plane 2 for the S-rdw case and L-rdw case is $7.7 \%$ and $20.6 \%$, respectively. At downstream plane 3, the tangential velocity reduction between HLC and HLC with the add-on device for S-rdw and L-rdw cases is $30.9 \%$ and $57 \%$, respectively. At downstream plane 4, the tangential velocity reduction between HLC and HLC with the add-on device for S-rdw and L-rdw cases is 54.3\% and $79.6 \%$, respectively.

For all studied cases, vorticity decreased steadily from a maximum at the center to nearly zero at the outer region of the vortices. Figure 5a shows that tiny vorticity patches exist at the outer regions of the vortex. This indicates that the entire vorticity shed by the half-span wing model is not deposited within the vortex core. Figure 6a shows that the number of tiny patches of vorticity has reduced, indicating that more vorticity has been deposited within the vortex core. The vorticity magnitude at the center of the vortex in Figure $6 \mathrm{a}$ is marginally higher than in Figure 5a, which supports the claim that more vorticity has diffused into the vortex core. In Figure 7 a, the vorticity magnitude at the vortex core has decreased, and the tiny patches of vorticity have increased in number. This indicates that the vorticity from the vortex core may have been deposited into the wake, reducing the vorticity magnitude. The circulation and strength of the vortex are reduced by the rejection of vorticity from the vortex 
core (Maxworthy, 1972).

Vorticity magnitude for the HLC with the add-on device is greater than the HLC case at downstream planes 1 and 2. This is because the tangential velocity magnitude of the resultant vortex at downstream plane 1 is greater. The vorticity reduces rapidly, as shown in Figures $4 b-c, 5 b-c, 6 b-c$, and $7 b-c$ in the appendix. Distinguishable vortex contours within the vortex core can be seen. The vortex core size is considerably larger than in the HLC case. At downstream plane 4 , the resultant vortex core is mostly broken down and diffused, as shown in Figure 7b-c. The vorticity magnitude recorded is much lower than the HLC case. This highlights the rapid diffusion of vorticity from the vortex core into regions outside the vortex core. The resultant vortex core has been significantly weakened, and its strength has been reduced. The L-rdw case vortex exhibits lower vorticity magnitudes than the S-rdw case vortex at all four downstream planes. The larger the size of the add-on device, the stronger the counter-sign vorticity injected into the vortex system, and the weaker the resultant vortex. The weak rolled-up resultant vortex causes the vortex core size to increase significantly, and also rejects vorticity into regions outside the resultant vortex core. The weakened resultant vortex is seen to diffuse rapidly.

The vorticity reduction from downstream plane 1 to downstream plane 4 for the HLC is merely $16.6 \%$. Since the vorticity magnitudes at downstream planes 1 and 2 exhibited by the resultant vortex are higher than the HLC case, the reduction in vorticity can only be compared at downstream planes 3 and 4 . The vorticity reduction between HLC and HLC with an add-on device at downstream plane 3 for the S-rdw case and L-rdw case is $42.3 \%$ and $74.9 \%$, respectively. At downstream plane 4, the vorticity reduction between HLC and HLC with an add-on device for S-rdw case and L-rdw case is $59 \%$ and $85.6 \%$, respectively.

The interaction of the wingtip vortex with the add-on device vortices upsets the roll-up process, and yields a weaker resultant vortex which causes an increase in the vortex core size and also the rejection of vorticity from the vortex core. It is established that the introduction of a reverse delta type add-on device enhances the dissipation rate of the resultant vortex.

The weaker vortices formed downstream of a wing with a reverse delta type add-on device are a desirable result. The weaker vortices will ensure that following aircraft are not being engulfed in strong swirling flows during approach, landings and take-offs. This will enable air traffic control centers to more tightly integrate air traffic by reducing the distance between aircraft in the traffic pattern. 


\section{Tangential Velocity Distributions}

The tangential velocity, $V_{\theta}$, is calculated as

$$
v_{\theta}(r)=\left.\frac{1}{k} \sum_{i=1}^{k} v_{\theta, i}(y, z)\right|_{r=\sqrt{y^{2}+z^{2}}}
$$

where $k$ is the number of points for each radius, and $r=\sqrt{y^{2}+z^{2}}$. For this study, $V_{\theta}$ is standardized by the free-stream velocity $V_{\infty}$ and plotted against the radial distance from the vortex centerline $r$, standardized by the half span $(\mathrm{b} / 2) . r_{\mathrm{c}}$ is defined as the vortex core radius, where maximum tangential velocity occurs (Saffman, 1978).

Figures $8 \mathrm{a}-8 \mathrm{~d}$ in the appendix show the tangential velocity distributions of HLC, HLC with S-rdw and HLC with L-rdw at the four investigated downstream planes. The tangential velocity distributions reach a maximum at the core radius, then vary inversely. Figure $8 \mathrm{a}$ indicates that the tangential velocity magnitude for the HLC case is lower than the tangential velocity magnitude for the add-on device cases. This corresponds with Figures $4 a-4 c$. In Figures $8 b-8 d$, the HLC case without the add-on devices exhibits higher tangential velocity magnitude than the HLC case with the add-on devices. This corresponds with Figures 4 - 7 for the HLC without the add-on devices. At a farther downstream location, the tangential velocity magnitude decreases for all studied cases due to vortex dissipation. The tangential velocity magnitude for the HLC with the add-on device cases decreases rapidly from downstream planes two to four.

The HLC vortex core radius is much smaller, compared to the HLC with the add-on device resultant vortex core radius at all four downstream locations. The difference in vortex core sizes is evident in the tangential velocity distributions. At $\mathrm{x} /(\mathrm{b} / 2)=0.021$, when the add-on device is used, consistent enlargement across the resultant vortex cores compared to the HLC vortex core appears - by a factor of 1.72 , and 2.23 for the S-rdw and L-rdw cases, respectively; at $\mathrm{x} /(\mathrm{b} / 2)=0.548$, by a factor of 1.93 and 2.31 for the $\mathrm{S}-\mathrm{rdw}$ and $\mathrm{L}$ rdw cases, respectively; at $\mathrm{x} /(\mathrm{b} / 2)=1.075$, by a factor of 2.72 and 3.62 for the S-rdw and L-rdw cases, respectively; and at $\mathrm{x} /(\mathrm{b} / 2)=2.387$, by a factor of 3.39 and 5.63 for the S-rdw and L-rdw cases, respectively. This implies that when the L-rdw is used, the resultant core radius size is 5.63 times larger than the core radius of the HLC case.

For HLC with S-rdw, the growth rate of the resultant vortex from plane 1 to plane 2 is $31.3 \%$; from plane 2 to $3,61.9 \%$; and from plane 3 to $4,35.3 \%$. For HLC with L-rdw, the growth rate of the resultant vortex from plane 1 to 2 is $21.7 \%$; from plane 2 to $3,79.4 \%$; and from plane 3 to $4,69.2 \%$. This indicates that the growth rate of the resultant vortex is greater than that of the wingtip 
vortex. This highlights the enormity of the diffusion of the resultant vortex caused when a reverse delta type add-on device is used. The enlarged resultant vortex is much weaker in strength, and expected to dissipate more rapidly than the HLC wingtip vortex.

\section{Circulation Distributions}

Circulation is estimated by

$$
\Gamma=\int_{A} \zeta d A
$$

which in turn yields

$$
\Gamma=2 \pi r v_{\theta}
$$

for an axisymmetric vortex (Anderson, 2001; Dobrev et al., 2008). For this study, circulation is normalized by $\mathrm{V}_{\infty}(\mathrm{b} / 2)$.

Figures $9 \mathrm{a}-9 \mathrm{~d}$ in the appendix show the circulation distributions for the HLC, HLC with S-rdw and HLC with L-rdw at the four investigated downstream planes.Between downstream planes 1 and 3 , the circulation magnitude of the HLC case increases significantly. The circulation magnitude of the HLC vortex between downstream planes 3 and 4 is almost steady, indicating that the vortex strength has not yet reduced. The HLC vortex is still compact at downstream plane 4 , and has not started to diffuse yet. The strength of the wingtip vortex will continue to increase.

The HLC with the add-on device shows that the circulation of the resultant vortex decreases steadily from downstream planes 1 to 4 . At downstream planes 1 and 2, the circulation magnitude of the resultant vortex is higher than the HLC vortex because the tangential velocity and vorticity magnitudes are higher, as shown in Figures 9a and 9b. For the S-rdw and L-rdw cases, the circulation magnitude decreases significantly as the add-on device injects counter-sign vorticity into the wingtip vortex. This weakens the resultant vortex, breaking down the resultant vortex core. Tiny individual vorticity patches are formed, which have lower vorticity magnitudes. The decrease of vorticity magnitude in the resultant vortex core causes a decline in its circulation (strength). At $\mathrm{x} /(\mathrm{b} / 2)=1.075$, the circulation magnitude for the S-rdw and Lrdw cases has decreased by $14.4 \%$ and $39.6 \%$, respectively. At $\mathrm{x} /(\mathrm{b} / 2)=2.387$, the circulation magnitude of the S-rdw and L-rdw cases has further decreased by $20.6 \%$ and $48.7 \%$, respectively.

There is significant decrease in the circulation magnitude from downstream planes 1 to 4 for the S-rdw and L-rdw cases. Thus, it can be said that in these cases, significant vortex decay has taken place as the resultant 
vortex core has started to deform and is broken into many tiny vorticity patches (Figure 6c). It is expected that further downstream, the circulation magnitude will continue to decrease, and eventually become insignificant. From the circulation distributions trend, the L-rdw case resultant vortex is likely to decay more rapidly, followed by the S-rdw and HLC cases, respectively. Figures $9 \mathrm{a}-$ $\mathrm{d}$ show that the enlarged resultant vortex is weaker in strength, and is expected to dissipate more rapidly than the HLC wingtip vortex.

\section{Aerodynamic Performance}

A six-component force balance was used to acquire the aerodynamic performance of the half-span wing model at four configurations. The reverse delta type add-on device's angle of attack was secured to $\alpha=+30^{\circ}$ for all cases. Figure 10a shows the lift coefficient $\left(\mathrm{C}_{\mathrm{L}}\right)$ and moment coefficient $\left(\mathrm{C}_{\mathrm{m}}\right)$ curves of all studied cases. The HLC exhibits the highest lift coefficient at $\alpha=18^{\circ}$, and it stalls between $\alpha=18^{\circ}$ and $\alpha=19^{\circ}$. The S-rdw and L-rdw configurations stall between $\alpha=19^{\circ}$ and $\alpha=20^{\circ}$. This indicates that by using an add-on device the wing stall can be delayed by approximately $1^{\circ}$. Lift coefficient reduction between the HLC, S-rdw and L-rdw cases is $2.9 \%$. Figure $10 \mathrm{~b}$ shows the drag coefficient $\left(\mathrm{C}_{\mathrm{D}}\right)$ curves for all studied cases. The drag coefficient increment for S-rdw case is $6.9 \%$ and $14 . \%$ for the L-rdw case. The findings of the study are listed in Table 1.

Table 1

Findings of the investigation.

\begin{tabular}{|c|c|c|c|c|c|}
\hline $\begin{array}{c}\text { Vortex Core } \\
\text { Radius }\end{array}$ & $\begin{array}{c}\text { Tangential } \\
\text { Velocity }\end{array}$ & Vorticity & Circulation & $\begin{array}{c}\text { Lift } \\
\text { Coefficient }\end{array}$ & $\begin{array}{c}\text { Drag } \\
\text { Coefficient }\end{array}$ \\
\hline $\begin{array}{c}+463 \% \\
\text { (factor of } \\
5.63 \text { ) }\end{array}$ & $-79.6 \%$ & $-85.6 \%$ & $-48.7 \%$ & $-2.9 \%$ & $+14.5 \%$ \\
\hline
\end{tabular}

Note. ' + ' indicates increase '-' indicates decrease

\section{Comparison of Lift and Drag Penalties with Other Techniques}

Table 2 provides a comparison of lift and drag penalties of the present study with other well-known wake vortex alleviation investigations. Table 2 shows that only Rossow's (1978) investigation yields a lower increment in drag than the study of the reverse delta type add-on device. However, the benefits of the present study regarding wake vortex alleviation are more superior to Rossow's study. 
Table 2

Comparison of lift and drag penalties with other wake vortex alleviation techniques.

\begin{tabular}{|c|c|c|c|}
\hline Authors & Device & $\begin{array}{c}\text { Lift } \\
\text { Reduction }\end{array}$ & $\begin{array}{c}\text { Drag } \\
\text { Increment }\end{array}$ \\
\hline V. J. Rossow, 1978 & Fins & $\begin{array}{c}\text { No lift } \\
\text { penalty }\end{array}$ & $10 \%$ \\
\hline $\begin{array}{c}\text { D. R. Croom \& G. T. } \\
\text { Holbrook, 1979 }\end{array}$ & Fins & $13.3 \%$ & $28.6 \%$ \\
\hline $\begin{array}{c}\text { E. Ozger, I. Schell \& D. } \\
\text { Jacob, 2001 }\end{array}$ & $\begin{array}{c}\text { Wing control surfaces } \\
\text { and fins }\end{array}$ & $7.0 \%$ & unavailable \\
\hline Breitsamter, 2011 & Double delta spoiler & $2.9 \%$ & unavailable \\
\hline Present Study & $\begin{array}{c}\text { Reverse delta type add- } \\
\text { on device }\end{array}$ & $2.9 \%$ & $14.5 \%$ \\
\hline
\end{tabular}

\section{Conclusion}

The vortex structures showed that there was a considerable reduction in tangential velocity, vorticity, and circulation when the reverse delta type addon devices were in use. The L-rdw case is more favourable, as it accomplishes a greater reduction in tangential velocity, vorticity and circulation magnitudes than the HLC case and the S-rdw case.

Between downstream planes 1 and 4, the maximum tangential velocity reduction recorded for the S-rdw case and the L-rdw case, compared to the HLC case, was $54.3 \%$ and $79.6 \%$, respectively. The maximum vorticity reduction recorded for the S-rdw case and the L-rdw case, compared to the HLC case, was $59.0 \%$ and $85.6 \%$, respectively; the maximum circulation reduction recorded for the S-rdw case and the L-rdw case, compared to the HLC case, was $20.6 \%$ and $48.7 \%$, respectively; the resultant vortex core radius relative to the HLC case increased by a factor of 3.39 and 5.63 for the S-rdw case and L-rdw case, respectively.

The resultant vortex strength is considerably weakened by the use of a reverse delta type add-on device. The weakened resultant vortex will continue to diffuse quickly and safeguard the following aircraft from encountering hazardous vortex flows. This will permit the reduction of aircraft separation distances and the amplification of aircraft handling capacity at major airports.The aerodynamic performance of the half-span wing model was moderately adversely affected by the use of a reverse delta type add-on device. The reduction in lift was $2.9 \%$, and the increase in drag was $14.5 \%$.

More extensive research is required to expose the maximum potential that a reverse delta type add-on device has, and it's capability to successfully alleviate the wake vortex hazard. Practical considerations will also need to be 
considered when implementing on real aircraft. The following is a list of potential problems that need to be discussed and/or studied:

- The extension of the add-on device (using actuators) in flight or the wind tunnel, with the wind on condition to note the immediate effect on the change in aerodynamic performance of the wing

- High accuracy experimental and computational investigations of the far wakes of aircraft with a reverse delta type add-on device to determine exactly how much spacing rules can be modified with no compromise to safety

- The effect of the mounting height of the reverse delta type addon device, as it could have a great impact on the half-span wing model aerodynamics and flow characteristics

- A reverse delta type add-on device at a combination of roll and pitch angles on a multi-element wing model in the wind tunnel 


\section{References}

Altaf, A., Thong, T. B., Ali Omar, A., \& Asrar, W. (2016). Impact of a reverse delta type add-on device on the flap-tip vortex of a wing. International Journal of Aviation, Aeronautics, and Aerospace, 3(3), 1-26.

Altaf, A., Thong, T. B., Omar, A. A., \& Asrar, W. (2016). Influence of a reverse delta type add-on device on wake vortex alleviation. AIAA Journal, 54(2), 625-636. doi: 10.2514/1.J054436

Anderson, J. D. (2001). Fundamentals of aerodynamics (3rd ed.). Singapore: McGraw Hill.

Andrews, W. H. (1970). Flight evaluation of the wing vortex wake generated by large jet transports. In: Aircraft Wake Turbulence and its Detection (pp. 287-288). New York, NY: Springer. doi: 10.1007/978-1-4684-8346-8_17.

Arndt, R.E.A., Arakeri, V.H., \& Higuchi, H. (1991). Some observations of tip vortex cavitation. Journal of Fluid Mechanics, 229, 269-289. doi: 10.1017/S0022112091003026

Babie, B. M., \& Nelson, R. C. (2004). Flow visualization study of far field wake vortex interactions. $11^{\text {th }}$ International Symposium on Flow Visualization. Notre Dame, IN: University of Notre Dame.

Breitsamter, C. (2011). Wake vortex characteristics of transport aircraft. Progress in Aerospace Sciences, 47(2), 89-134. doi: 10.1016/j.paerosci.2010.09.002

Corsiglia, V. R., Jacobsen, R. A., \& Chigier, N. (1971). An experimental investigation of trailing vortices behind a wing with a vortex dissipater. In: Aircraft Wake Turbulence and its Detection (pp 229-242). New York, NY: Springer. doi: 10.1007/978-1-4684-8346-8_14

Croom, D. R., \& Holbrook, G. T. (1979). Low speed wind tunnel investigation of wing fins as trailing vortex alleviation devices on a transport airplane model. NASA Technical Paper 1453.

Dobrev, I., Maalouf, B., Troldborg, N., \& Massouh, F. (2008). Investigation of the wind turbine vortex structure. 14th International Symposium on Applications of Laser Techniques to Fluid Mechanics. Lisbon, Portugal: The Calouste Gulbenkian Foundation. 
Durston, D. A., Walker, S. M., Driver, D. M., Smith, S. C., \& Savas, O. (2005). Wake-vortex alleviation flowfield studies. Journal of Aircraft, 47(4), 894-907. doi: 10.2514/1.7904

Elsenaar, B. (2006). Improved wake vortex separation ruling and reduced wake signatures. WakeNet2-Europe in Ccollaboration with WakeNet-USA, 1, 1-51. doi: 10.1016/j.ast.2007.09.008

Fabre, D., Jacquin, L., \& Loof, A. (2002). Optimal perturbations in a fourvortex aircraft wake in counter-rotating configuration. Journal of Fluid Mechanics, 451, 319-328. doi: 10.1017/S0022112001006954

Lee, T., \& Pereira, J. (2013). Modification of static-wing tip vortex via a slender half-delta wing. Journal of Fluids and Structures, 43, 1-14. doi: 10.1016/j.jfluidstructs.2013.08.004

Matalanis, C. G., \& Eaton, J. K. (2007). Wake vortex alleviation using rapidly actuated segmented Gurney flaps. The Stanford Thermal and Fluid Sciences Affiliates and the Office of Naval Research. Stanford, CA: Stanford University.

Maxworthy, T. (1972). The structure and stability of vortex rings. Journal of Fluid Mechanics, 51, 15-32. doi: 10.1017/S0022112072001041

McGowan, W. A. (1968). Trailing vortex hazard. SAE Technical Paper 680220. doi: $10.4271 / 680220$

Ortega, J. M., Bristol, R. L., \& Savas, O. (2002). Wake alleviation properties of triangular-flapped wings. AIAA Journal, 40(4), 709-721. doi:

$10.2514 / 2.1703$

Ozger, E., Schell, I., \& Jacob, D. (2001). On the structure and attenuation of an aircraft wake. Journal of Aircraft, 38(5), 878-887. doi:10.2514/2.2847

Patterson, J. C. (1975). Vortex attenuation obtained in the Langley vortex research facility. Journal of Aircraft, 12(9), 745-749. doi: 10.2514/3.59865

Rossow, V. J. (1978). Effect of wing fins on lift-generated wakes. Journal of Aircraft, 15(3), 160-167. doi:10.2514/3.58335

Saffman, P. G. (1978). The number of waves on unstable vortex rings. Journal of Fluid Mechanics, 84(4), 625-639. doi:10.1017/S0022112078000385 
Savas, O. (2005). Experimental investigations on wake vortices and their alleviation. Academie des Sciences, 6(4-5), 415-429. doi: 10.1016/j.crhy.2005.05.004

Veillette, P. R. (2002). Data show that U.S. wake-turbulence accidents are most frequent at low altitude and during approach and landing. Flight Safety Digest, 21(3-4), 1-56.

Zhang H. J., Zhou, Y., \& Whitelaw, J. H. (2006). Near field wing-tip vortices and exponential vortex solution. Journal of Aircraft, 43(2), 445-449. doi: $10.2514 / 1.15938$ 


\section{Appendix}

Figure 4. Velocity Vectors, Tangential Velocity Magnitude and Vorticity Magnitude at $x /(b / 2)=0.021$.
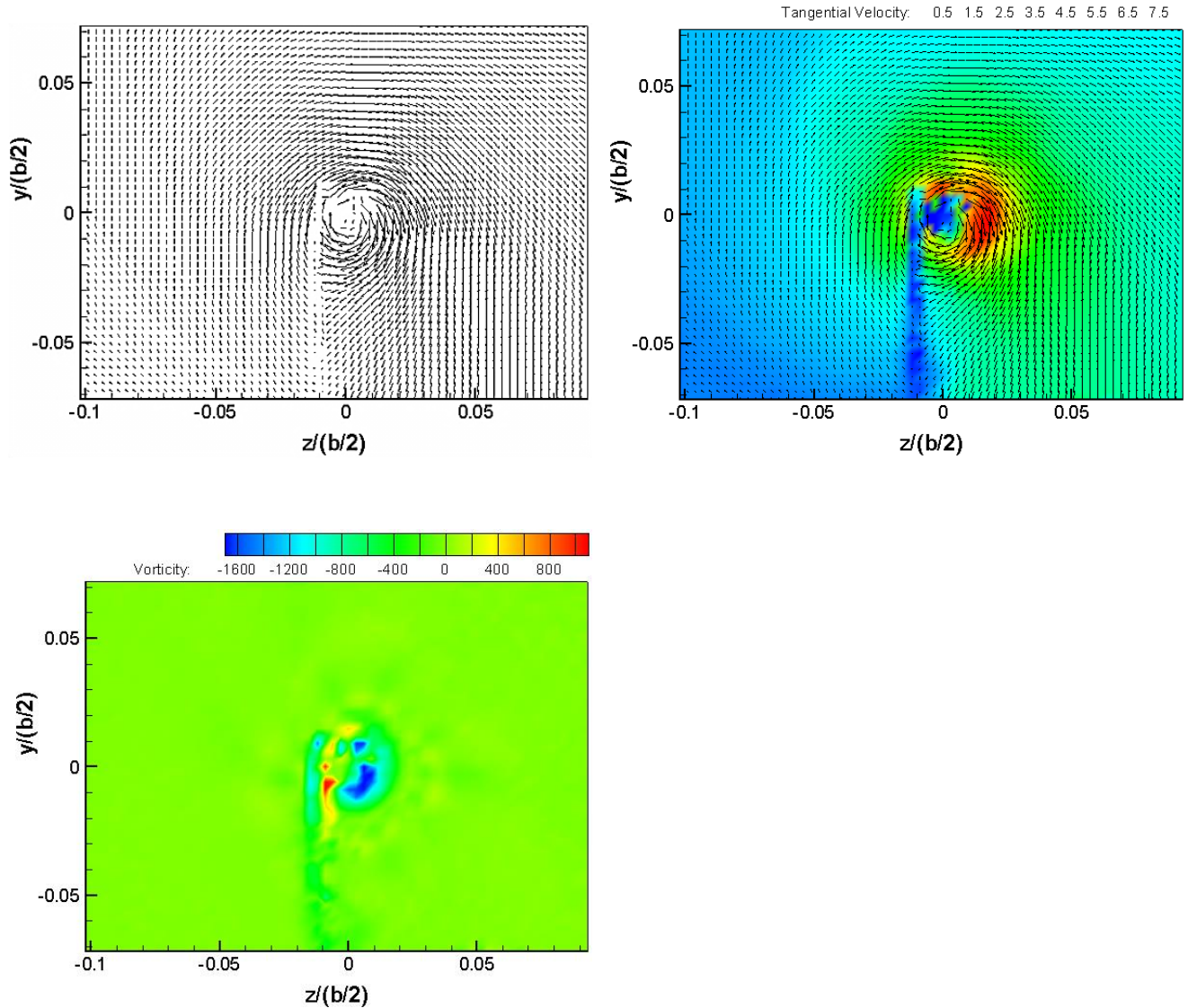

a) HLC case, $\alpha=7.7^{\circ}$.
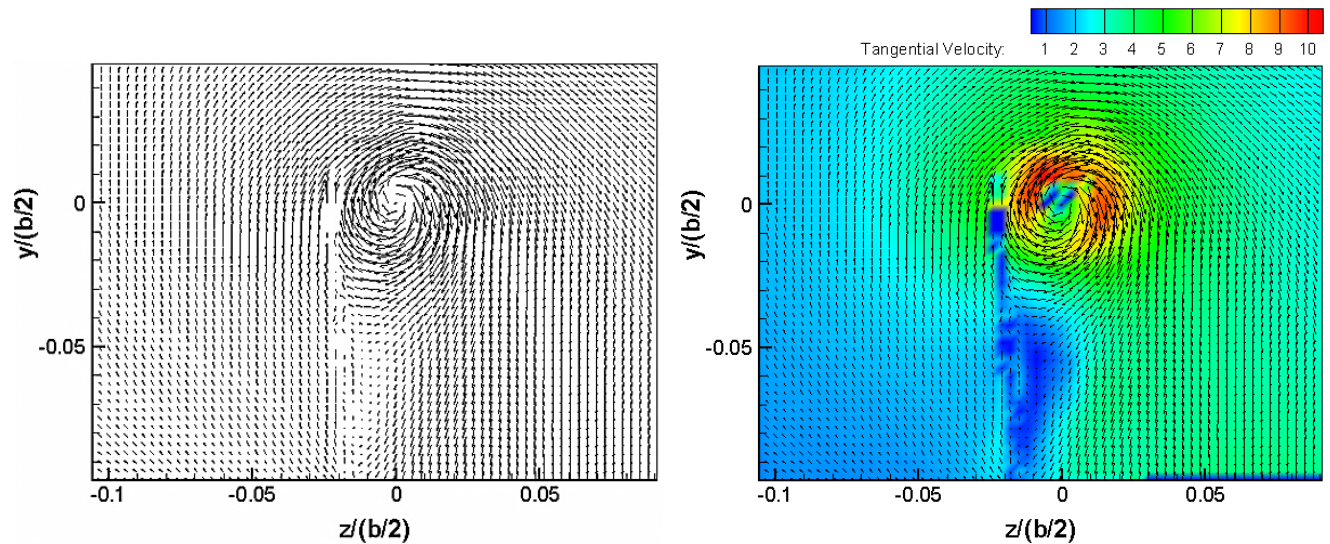
International Journal of Aviation, Aeronautics, and Aerospace, Vol. 4 [2017], Iss. 3, Art. 7

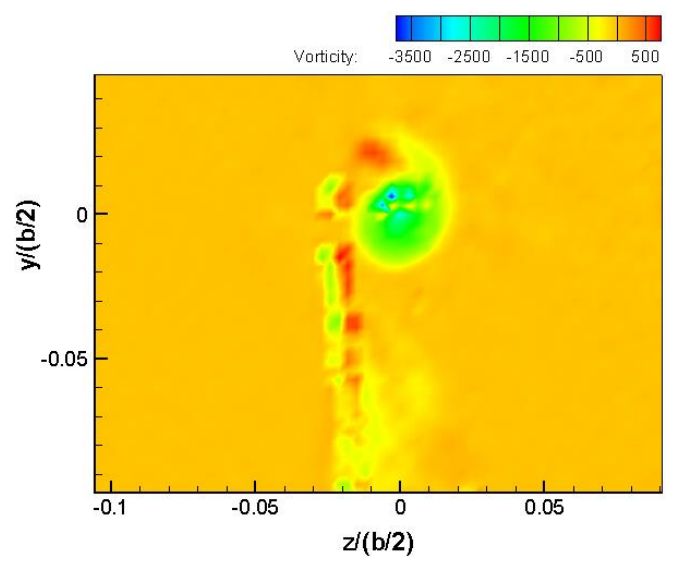

b) HLC with S-rdw, $\alpha=9.7^{\circ}, \alpha_{\text {-rdw }}=+30^{\circ}$.
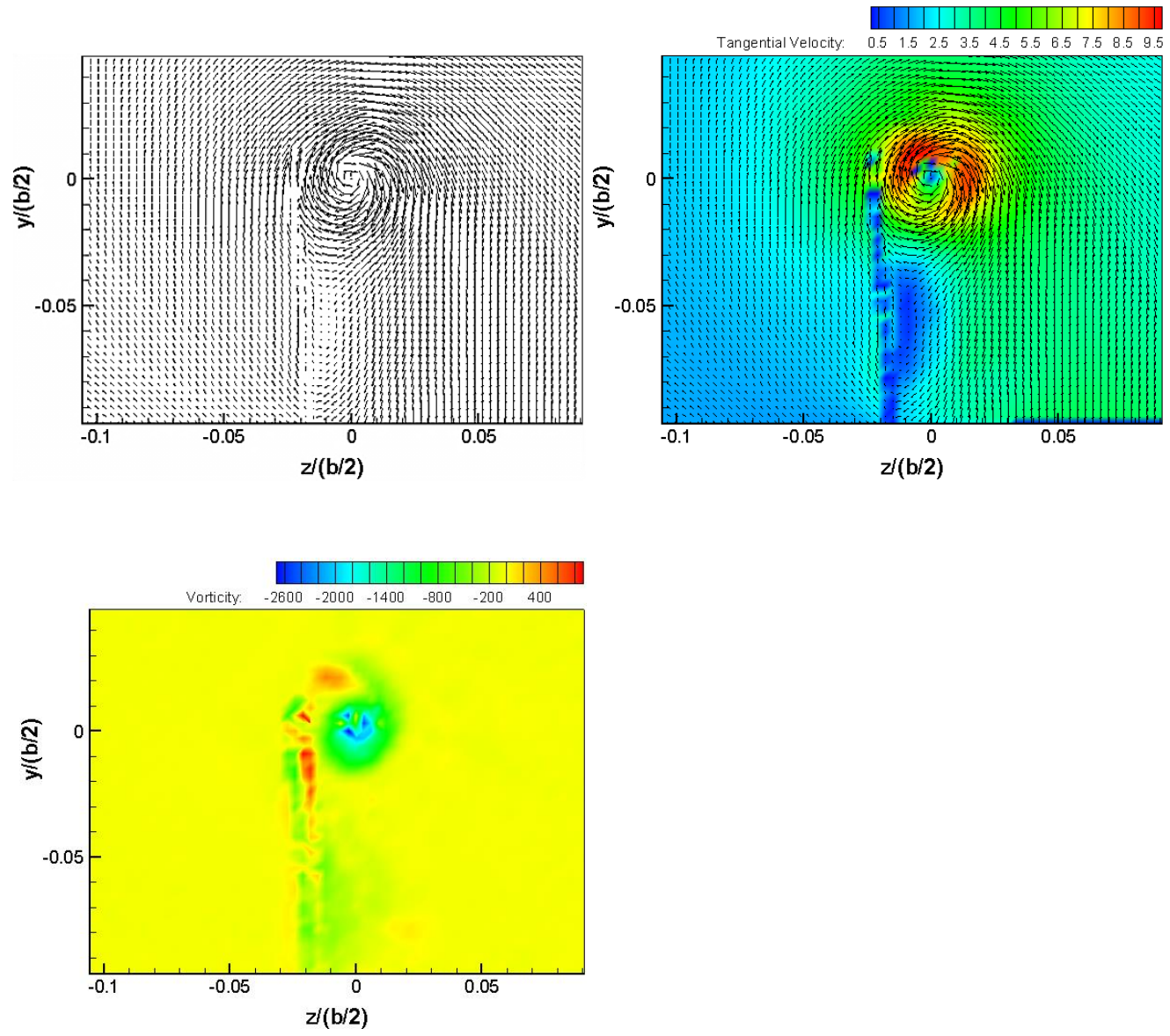

c) HLC with L-rdw, $\alpha=9.7^{\circ}, \alpha_{\mathrm{Lrdw}}=+30^{\circ}$. 
Figure 5. Velocity Vectors, Tangential Velocity Magnitude and Vorticity Magnitude at $x /(b / 2)=0.548$.
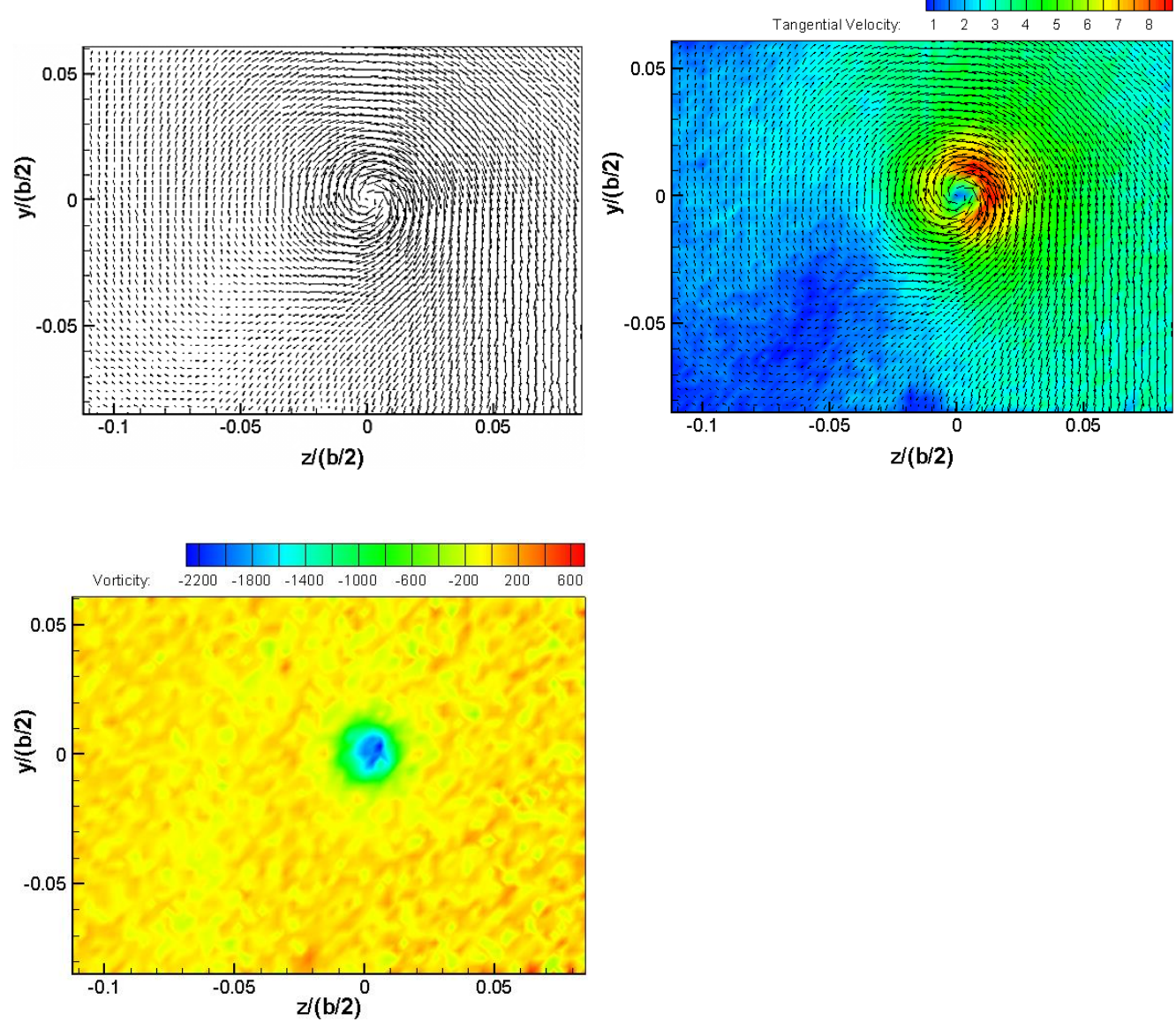

a) HLC case, $\alpha=7.7^{\circ}$.
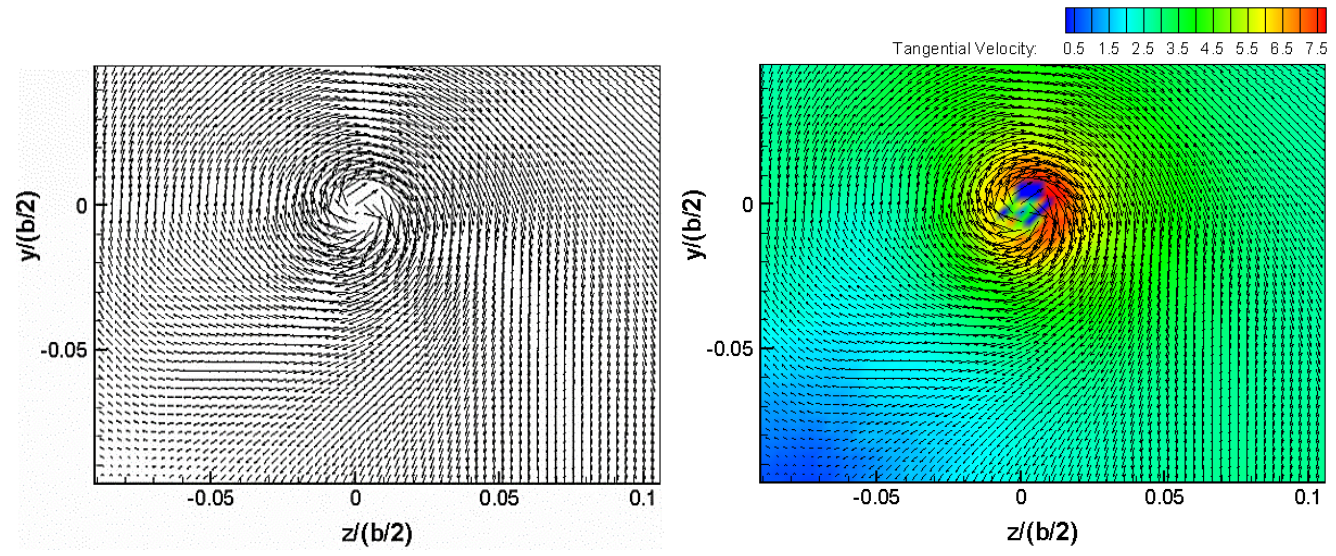
International Journal of Aviation, Aeronautics, and Aerospace, Vol. 4 [2017], Iss. 3, Art. 7

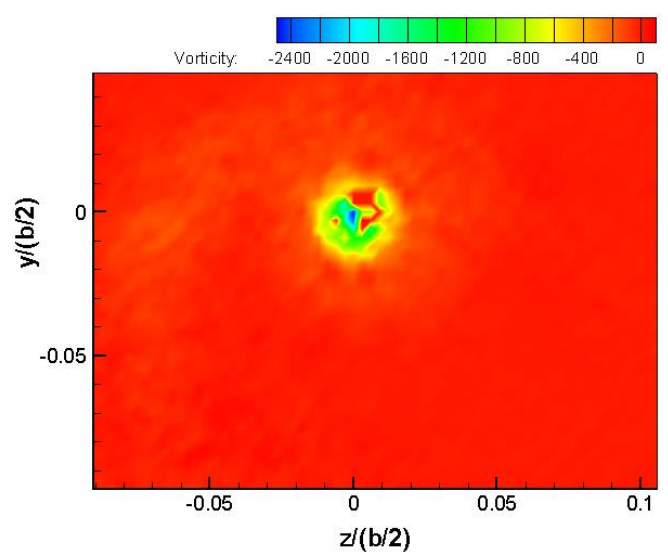

b) HLC with S-rdw, $\alpha=9.7^{\circ}, \alpha_{\text {-rdw }}=+30^{\circ}$.
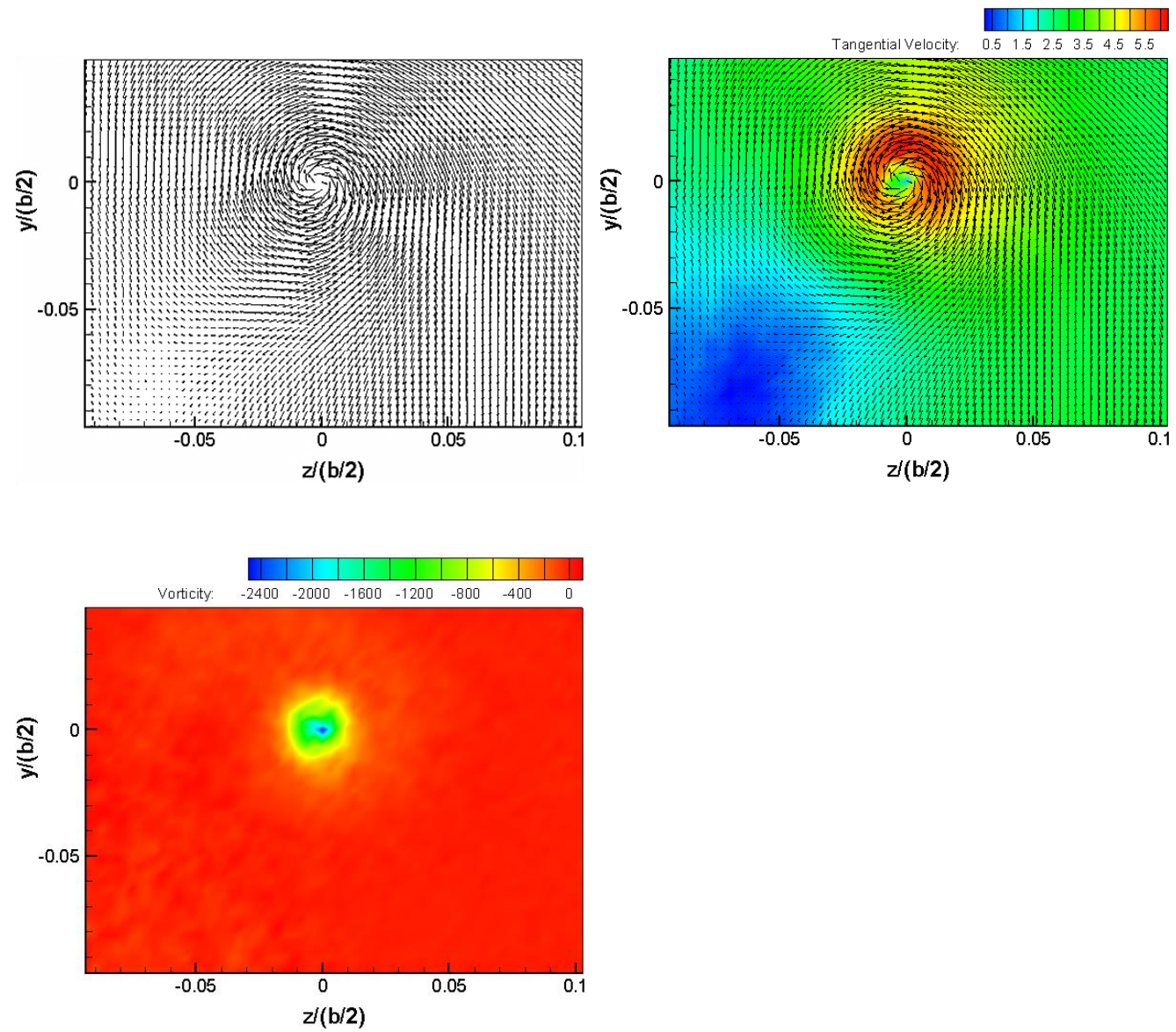

c) HLC with L-rdw, $\alpha=9.7^{\circ}, \alpha_{\mathrm{Lrdw}}=+30^{\circ}$. 
Figure 6. Velocity Vectors, Tangential Velocity Magnitude and Vorticity Magnitude at $x /(b / 2)=1.075$.
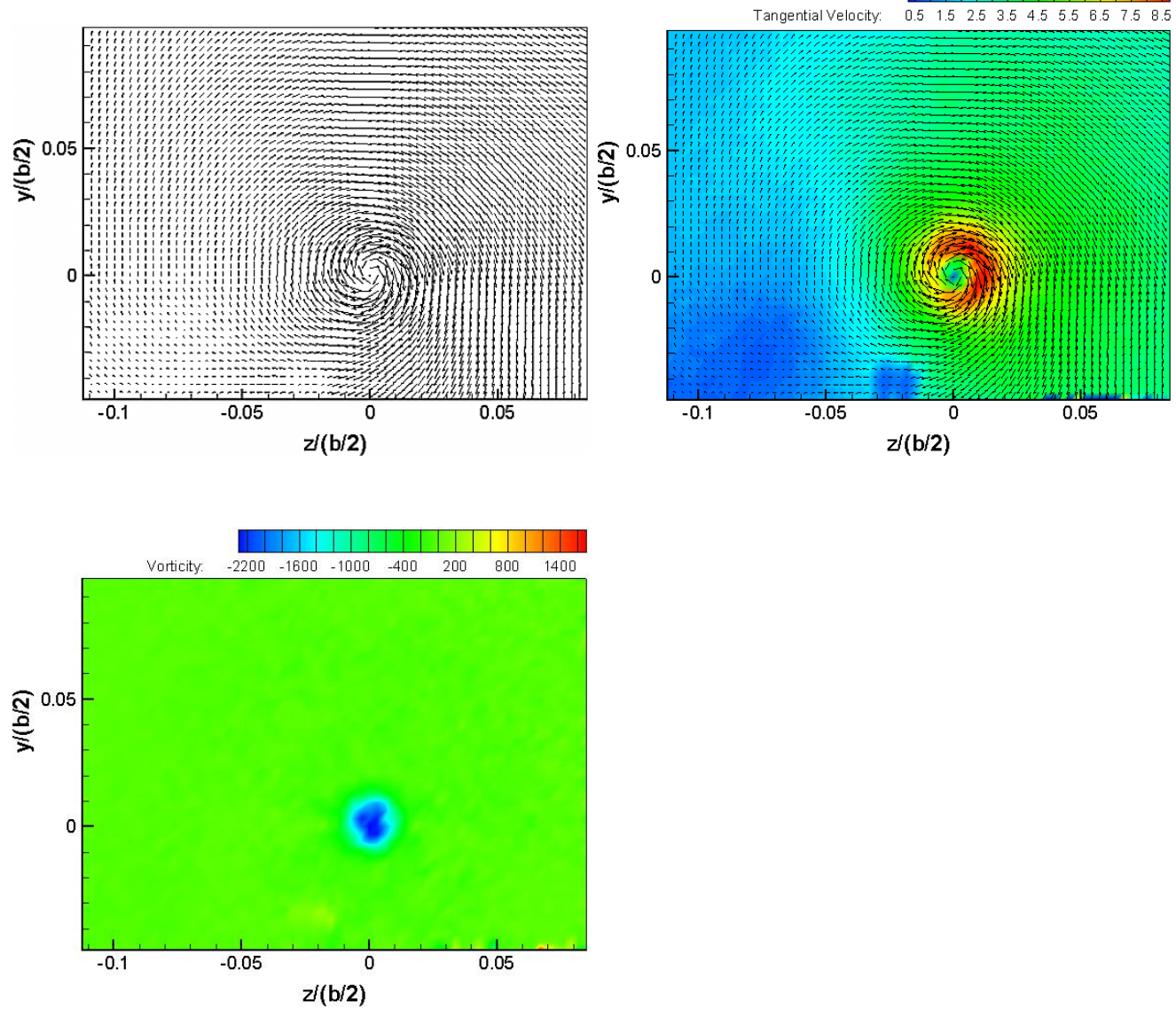

a) HLC case, $\alpha=7.7^{\circ}$.
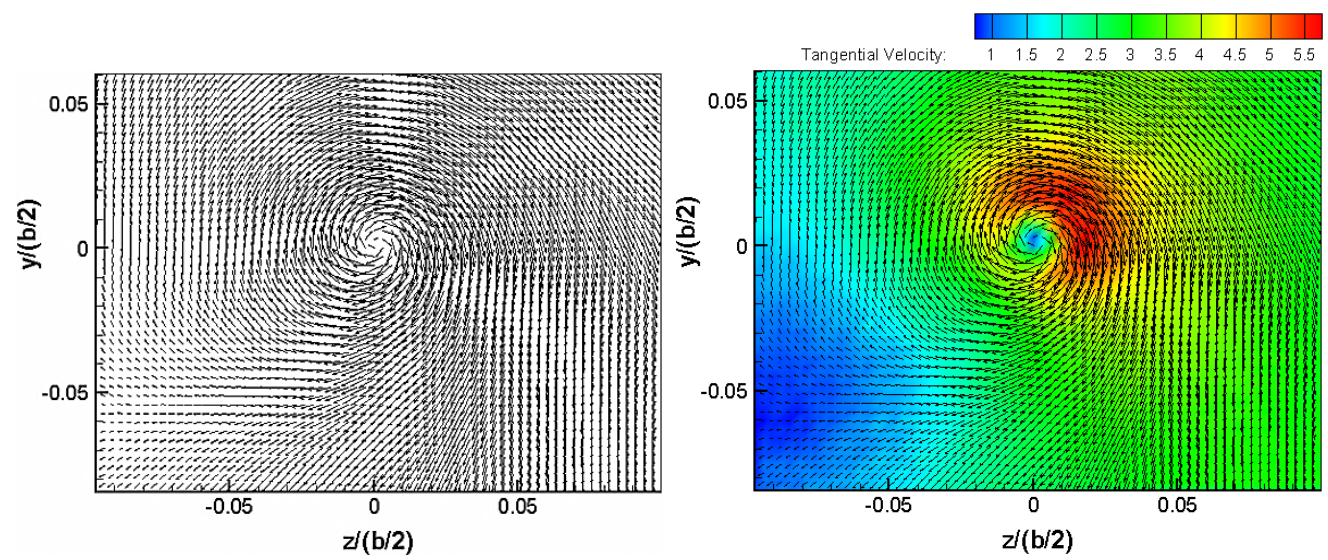
International Journal of Aviation, Aeronautics, and Aerospace, Vol. 4 [2017], Iss. 3, Art. 7

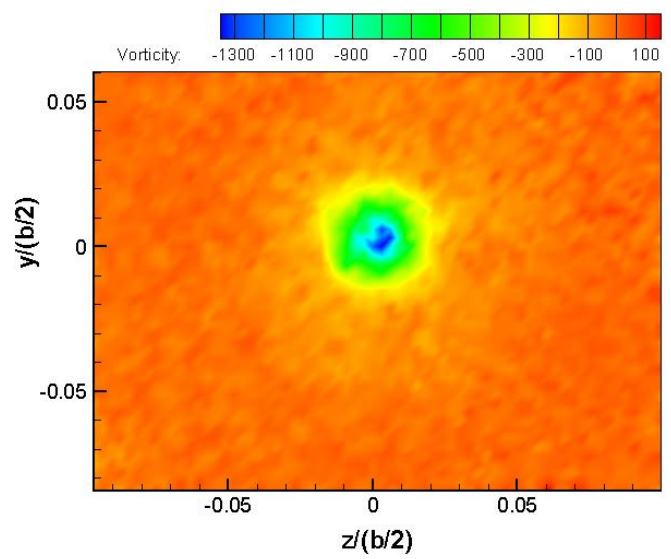

b) HLC with S-rdw, $\alpha=9.7^{\circ}, \alpha_{S-\text {-rdw }}=+30^{\circ}$.
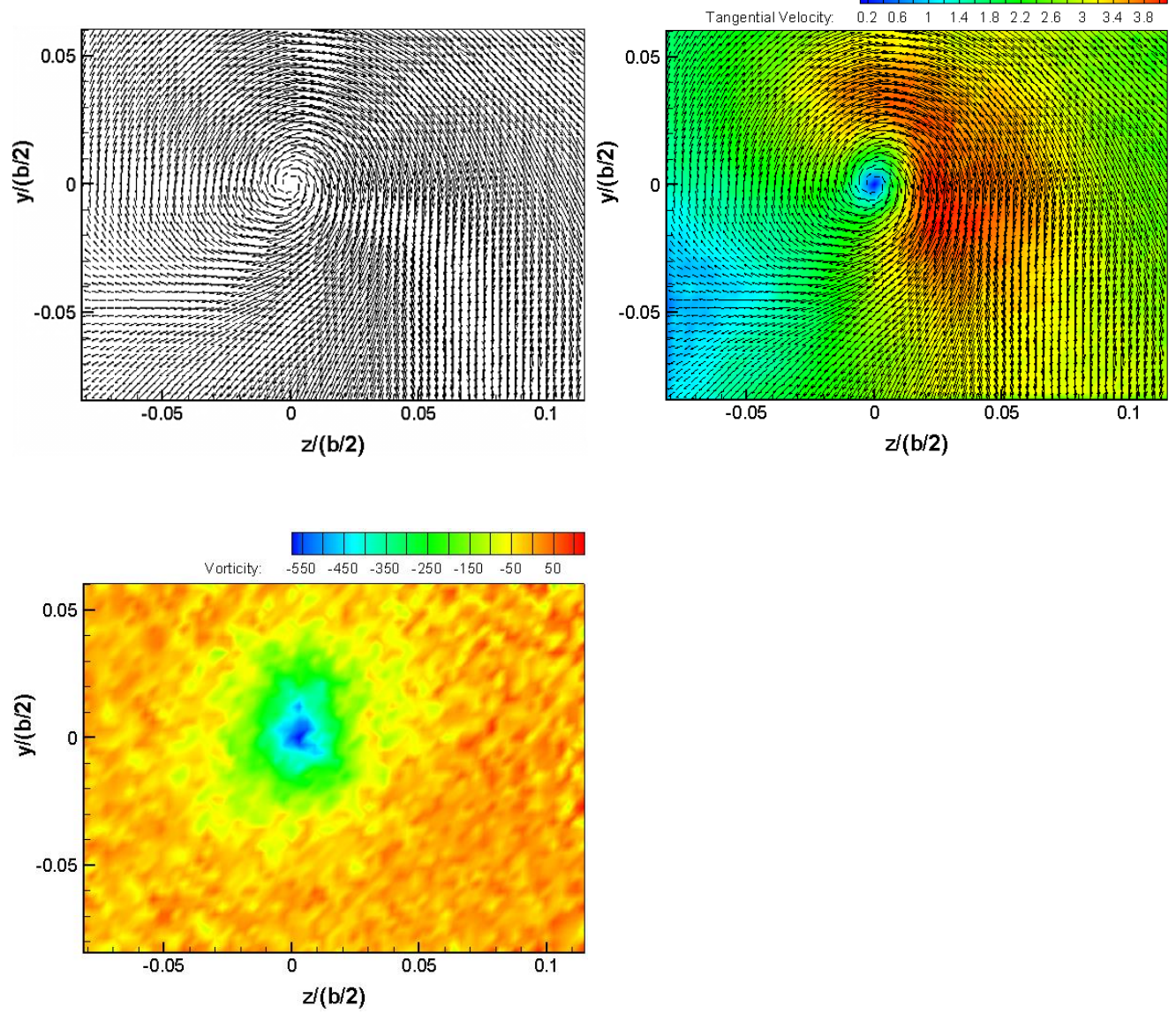

c) HLC with L-rdw, $\alpha=9.7^{\circ}, \alpha_{\mathrm{Lrdw}}=+30^{\circ}$. 
Figure 7. Velocity Vectors, Tangential Velocity Magnitude and Vorticity Magnitude at $x /(b / 2)=2.387$.
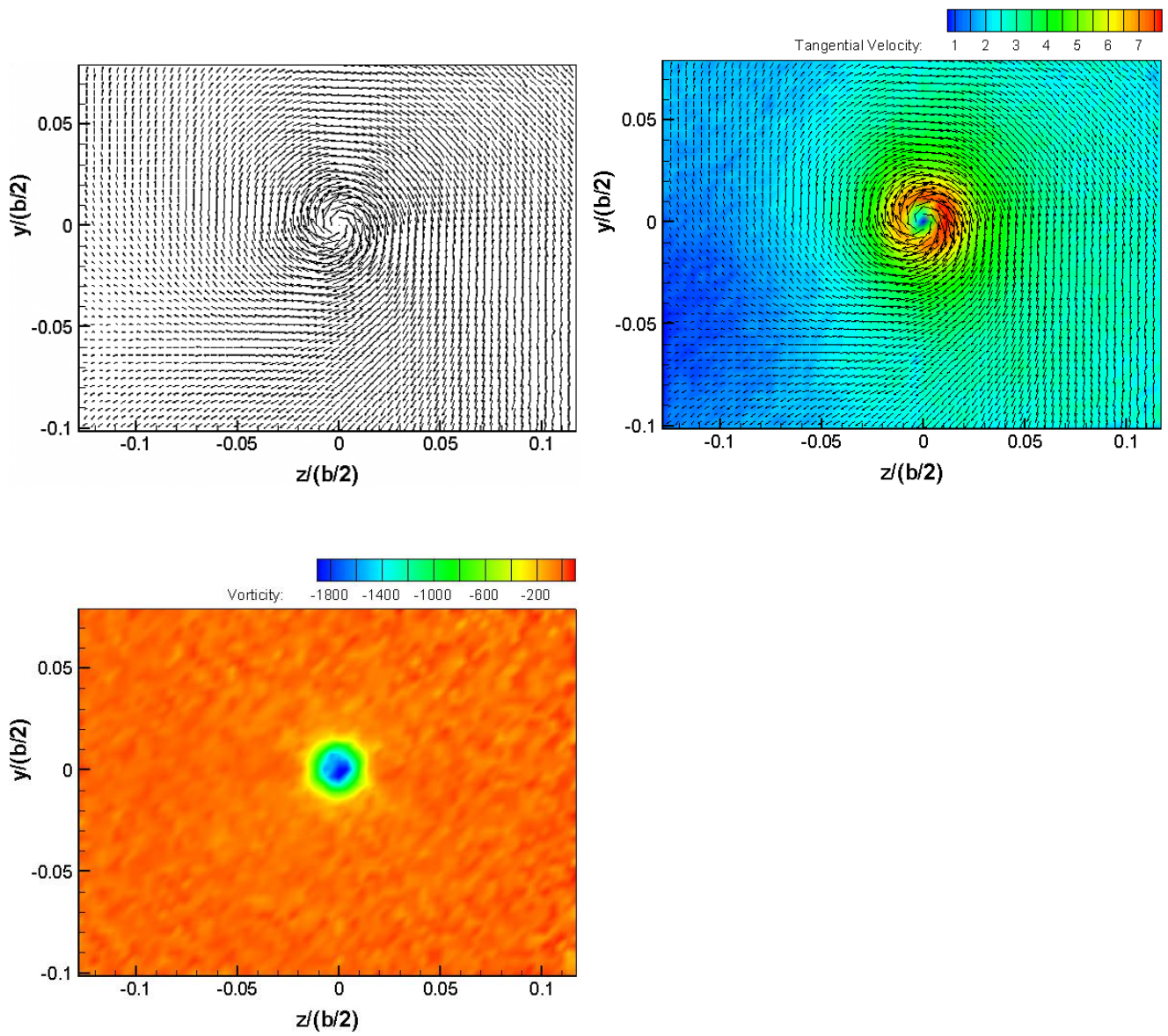

a) HLC case, $\alpha=7.7^{\circ}$.
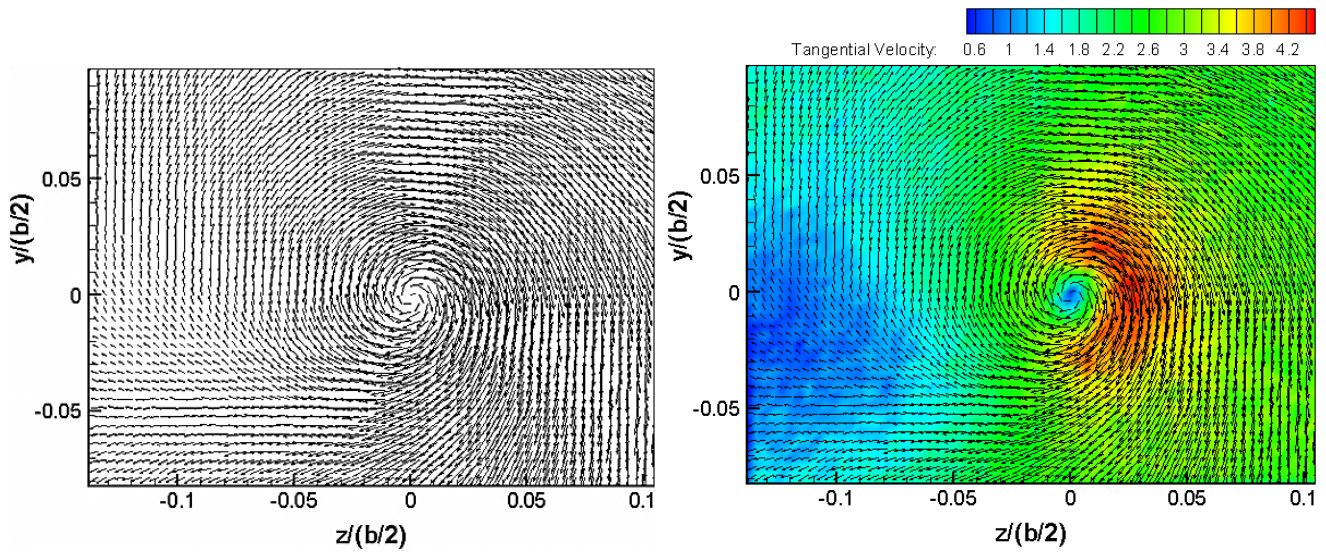
International Journal of Aviation, Aeronautics, and Aerospace, Vol. 4 [2017], Iss. 3, Art. 7

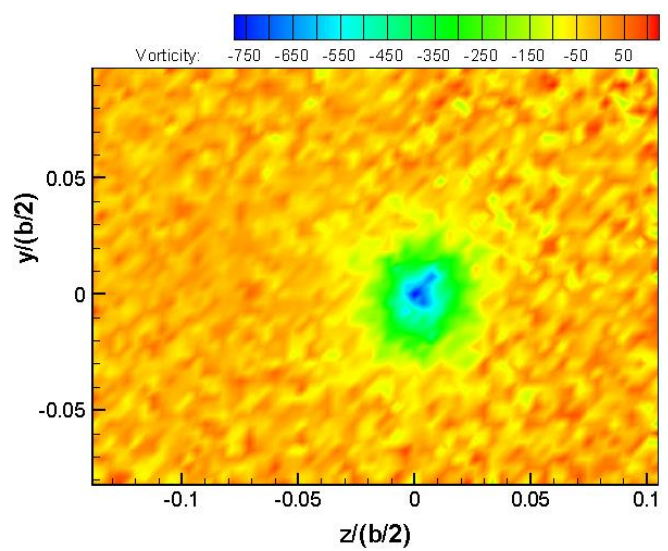

b) HLC with S-rdw, $\alpha=9.7^{\circ}, \alpha_{\text {S-rdw }}=+30^{\circ}$.
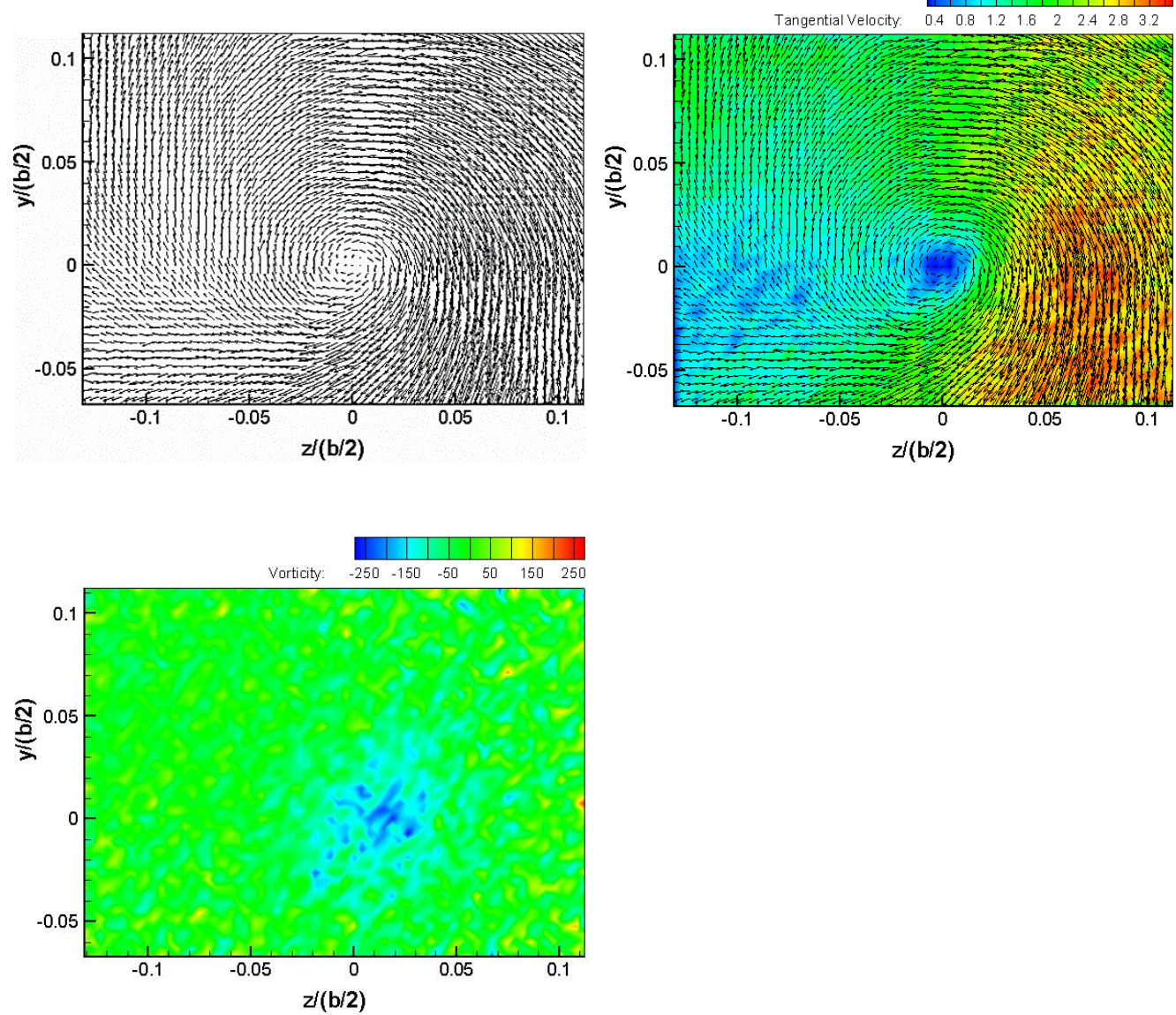

c) HLC with L-rdw, $\alpha=9.7^{\circ}, \alpha_{\mathrm{Lrdw}}=+30^{\circ}$. 
Figures $8 a, 8 b, 8 c, \& 8 d$. Non-dimensional tangential velocity distributions of HLC, HLC with S-rdw and HLC with L-rdw at (a) $x /(b / 2)=0.021$, (b) $x /(b / 2)=0.548$, (c) $x /(b / 2)=1.075$ and (d) $x /(b / 2)=2.387$.

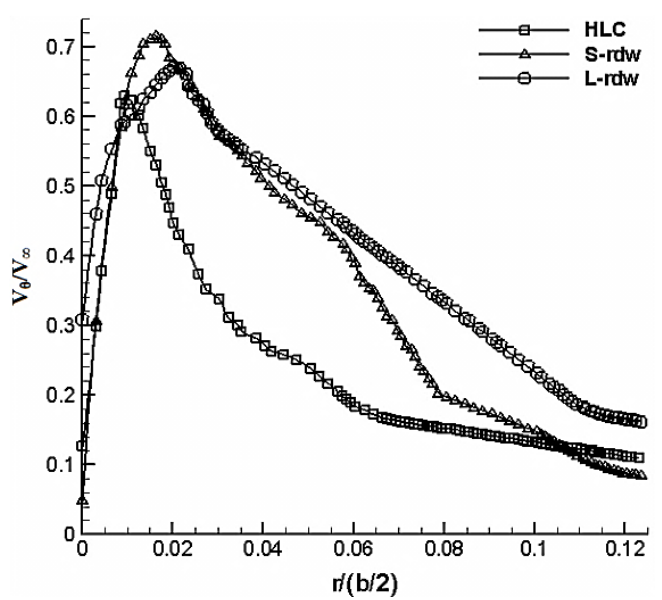

(a)

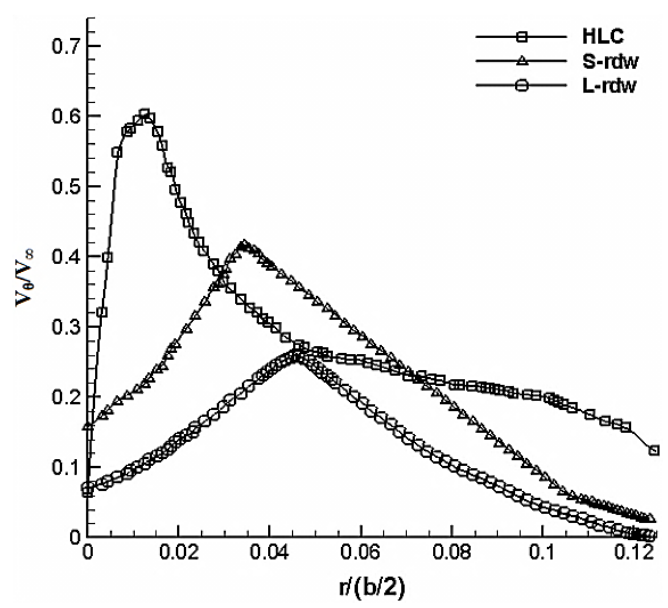

(c)

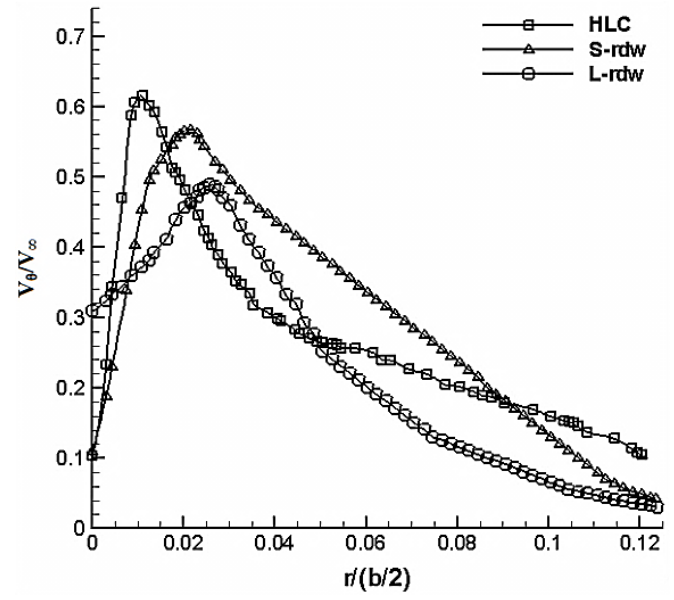

(b)

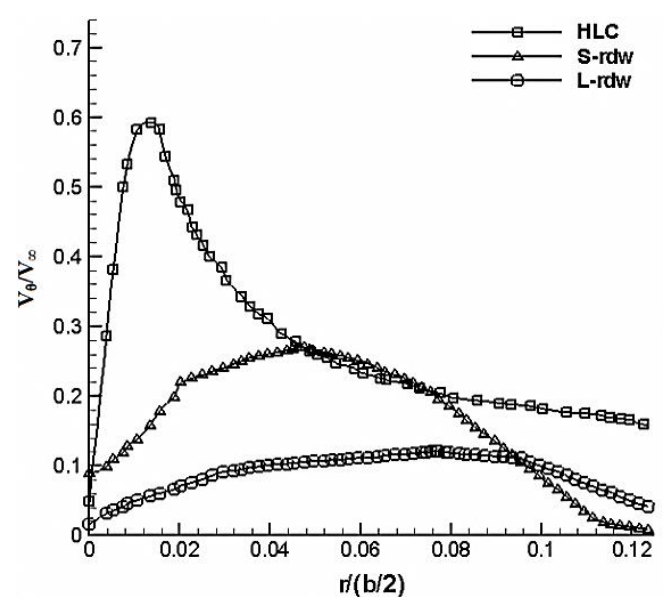

(d) 
Figures $9 a, 9 b, 9 c$, \& $9 d$. Vortex strength $\Gamma / V_{\infty}(b / 2)$ versus radius $r /(b / 2)$ of vortex of HLC, HLC with S-rdw and HLC with L-rdw at (a) $x /(b / 2)=0.021$, (b) $x /(b / 2)=0.548$, (c) $x /(b / 2)=1.075$ and $(\mathrm{d}) x /(b / 2)=2.387$.

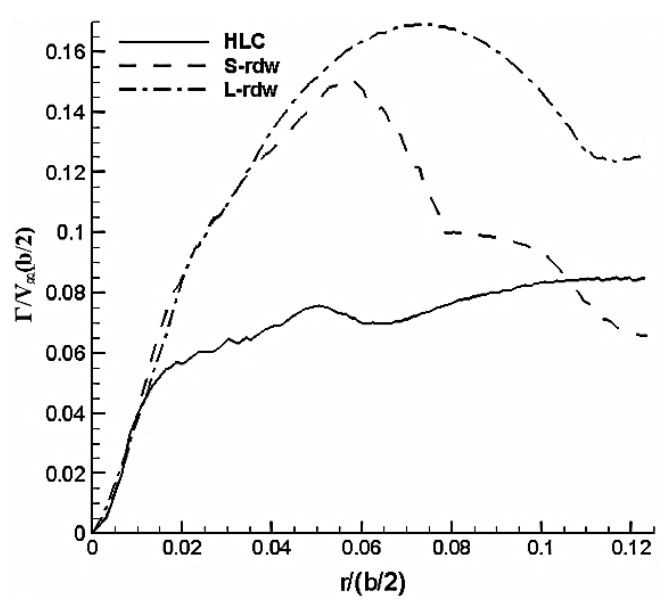

(a)

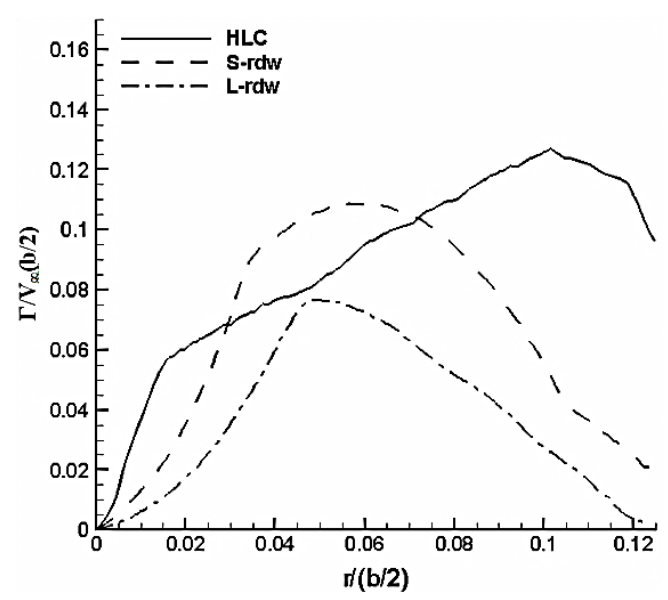

(c)

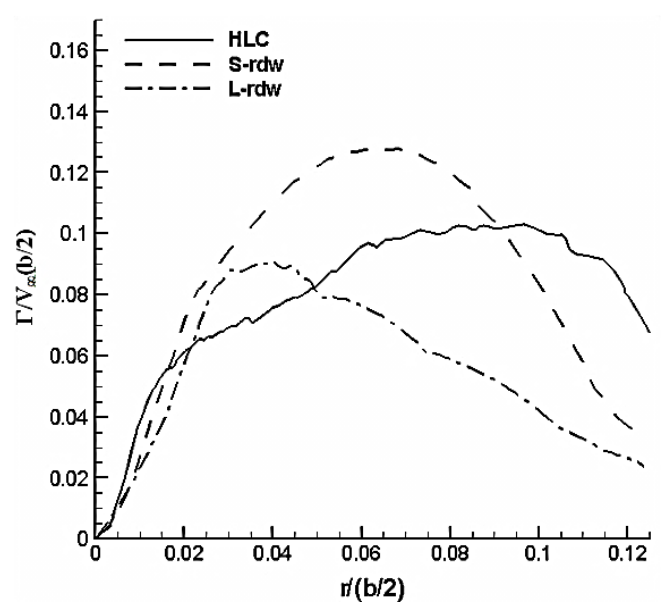

(b)

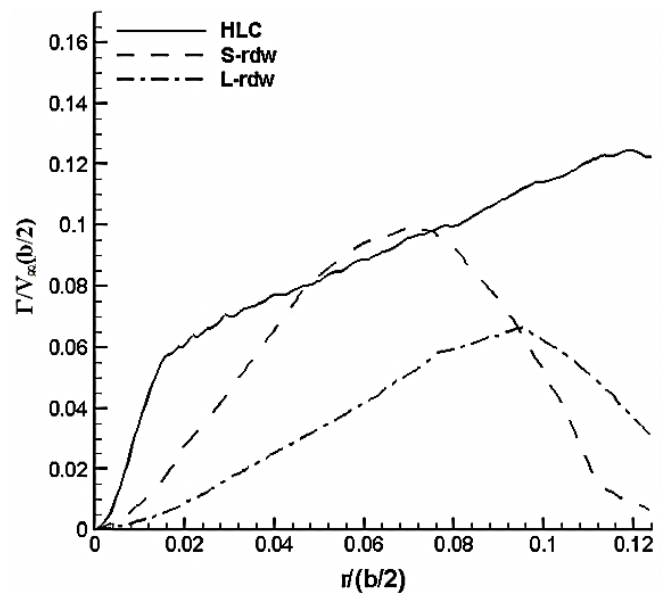

(d) 
Figures $10 a, 10 b, 10 c, \& 10 d$. Aerodynamic performance of the Plain Wing, HLC, HLC with S-rdw and HLC with L-rdw.

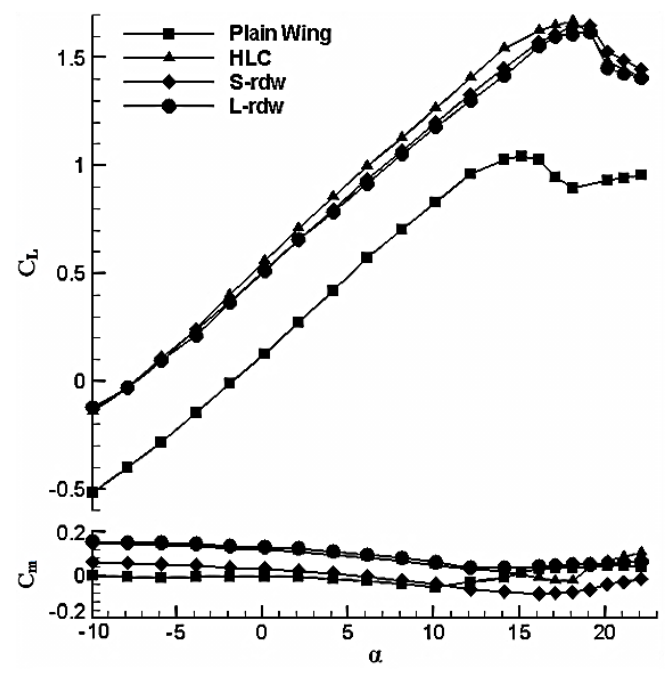

(a) $C_{L}$ vs $\alpha$ and $C_{m}$ vs $\alpha$

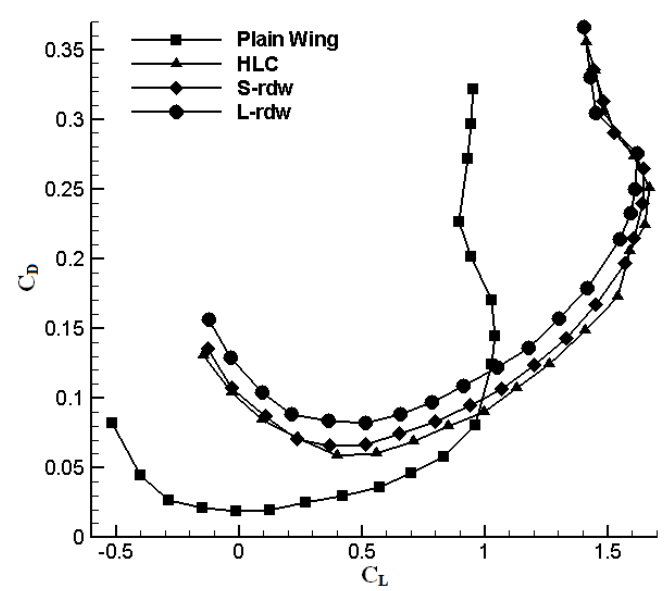

(c) $C_{D}$ vs $C_{L}$

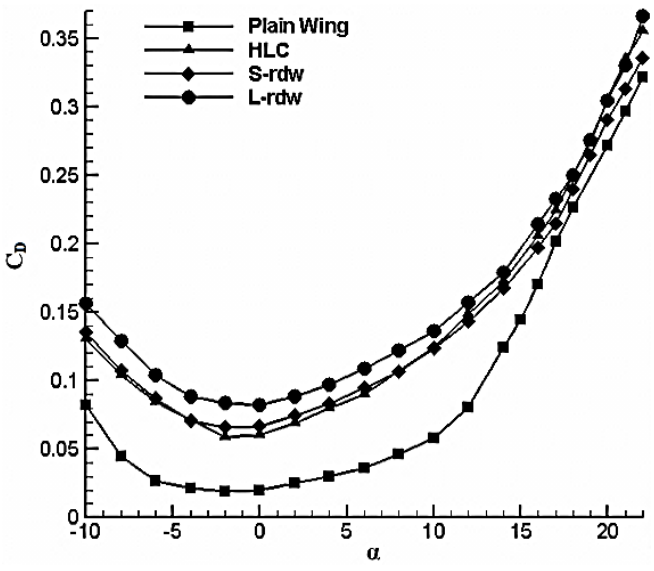

(b) $C_{D}$ vs $\alpha$

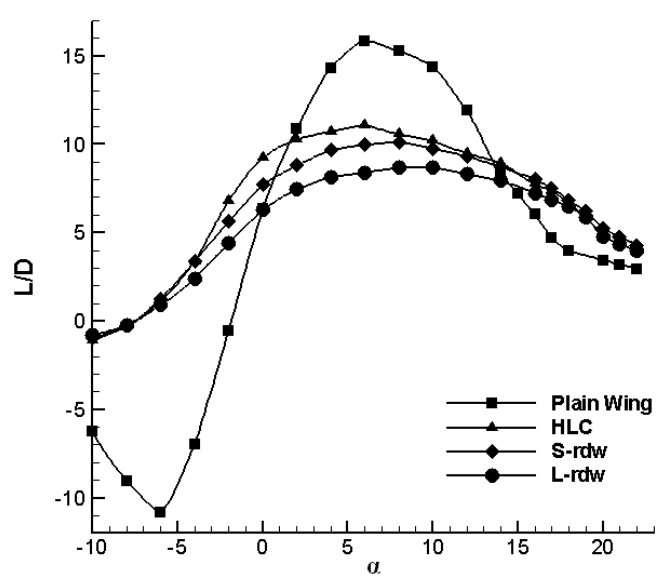

(d) $\mathrm{L} / \mathrm{D}$ vs $\alpha$ 
